\title{
GC-MS ANALYSIS OF SOME PLASTIC COMPONENTS FROM 1997-2003 COMPUTER MAIN BOARDS
}

\author{
DALMA KOVACS ${ }^{a}$, DORINA SIMEDRU ${ }^{a}$, MELINDA KOVACS ${ }^{a, *}$
}

\begin{abstract}
Recycling is one of most important steps toward circular economy. Since the quantity of waste of electrical and electronic equipment (WEEE) is increasing rapidly, it became crucial to know its composition to find adequate recycling solutions. Following this trend, the present study aims to find the major components of plastic components from 1997-2003 computer main boards. A new GC-MS method was developed and used to quantify the main volatile organic compounds of polystyrene PS (benzene, ethylbenzene), acrylonitrile butadiene styrene ABS (acetophenone, styrene, butyldiglycol) and polypropylene PP (n-Tetradecane, n-Hexadecane and n-Heptadecane). The extraction method was carried out using a saline water solution (10\% saline content; w:v) to extract the volatile compounds on SPME fibers under continuous agitation at $55{ }^{\circ} \mathrm{C}$. The analytical method used a complex temperature program and a HP-5ms fused-silica capillary column of $30 \mathrm{~m}$ length $\times 0.25 \mathrm{~mm}$ I.D. $\times 0.25 \mu \mathrm{m}$ film thickness (Restek, USA) to achieve separation of the compounds. The investigation of the major components of plastic components from 1997-2003 computer main boards using the developed method showed a decrease of ABS and PP major components from 1997 to 2003 and an increase of the major components from PS.
\end{abstract}

Keywords: WEEE, polystyrene, acrylonitrile butadiene styrene, polypropylene, GC-MS

\section{INTRODUCTION}

According to European Commission (2019), waste of electrical and electronic equipment (WEEE) is increasing rapidly in EU, with 9 million tons generated in 2005, and expected to grow to more than 12 million tons by 2020 [1]. It is considered that approximately $20 \%$ of WEEE consist in different

\footnotetext{
a INCDO-INOE 2000, Subsidiary Research Institute for Analytical Instrumentation ClujNapoca, 67 Donath, 400293, Cluj-Napoca, Romania

*Corresponding author: melinda.kovacs@icia.ro
} 
type of plastics [2]. Plastics are the best choice in electrical and electronic equipment (EEE) because they reduce the cost of the product but in the same time, they make a significant improvement of EEE properties. They are used for insulation, noise reduction, sealing, housing, interior structural parts, functional parts, interior electronic components among other uses [3]. From almost 300 different types of plastics that can be found in WEEE, acrylonitrile butadiene styrene (ABS, 30-35\%), high impact polystyrene (HIPS, 20-25\%) and polypropylene (20-30\%) are the most used [4,5]. These plastics can be recycled using expensive and longtime processes: they are chopped, washed and sorted by type [6].

Acrylonitrile butadiene styrene (ABS) is one of the major components of plastic WEEE [6]. It is a triblock copolymer with attractive mechanical properties and convenient processing conditions [7-9].

Polypropylene is considered to be the lightest and most versatile polymers due to its capacity to undergo various manufactured processes. It is one of the most common types of microplastic found in the marine environment [10].

Polystyrene is a transparent, non-biodegradable polymer which is considered to be relatively chemically inert. It is waterproof and resistant to breakdown by many acids and bases [11].

Due to their intense use and their chemical nature, it is important to know their quantity in order to find adequate techniques for their recycling.

Several analytical methods are mostly used to investigated the presence of polymers in WEEE: Fourier transform infrared (FTIR) [12-14], Raman spectroscopy [15-17] and pyrolysis GC-MS [18, 19]. Even if these methods were proved to be useful in characterization of polymers more accurate methods for their determination are required since these polymers are considered to be environment micropollutants.

The purpose of this study is to develop an GC-MS method suitable for the determination of polymers from WEEE and to establish the chemical profile (the presence of polystyrene (PS), acrylonitrile butadiene styrene (ABS) and polypropylene (PP)) of plastic components from 1998-2003 computer main boards by quantifying the volatile organic compounds present in these polymers.

\section{RESULTS AND DISCUSSION}

Plastic components of 4 computer main boards produced between 1997-2003 were analyzed in order to obtain their plastic profile (the quantity of polystyrene (PS), acrylonitrile butadiene styrene (ABS) and polypropylene (PP)). 
Figure 1 presents the total ion chromatogram of two samples after GC-MS analysis.

Several volatile organic compounds characteristic to each of these polymers were determined by GC-MS. The results expressed as percentage concentration from the total HS-SPME extracted compounds are presented in Table 1. Since ethylbenzene is a main component of both polystyrene (PS) and acrylonitrile butadiene styrene (ABS) its provenience cannot be precisely established.
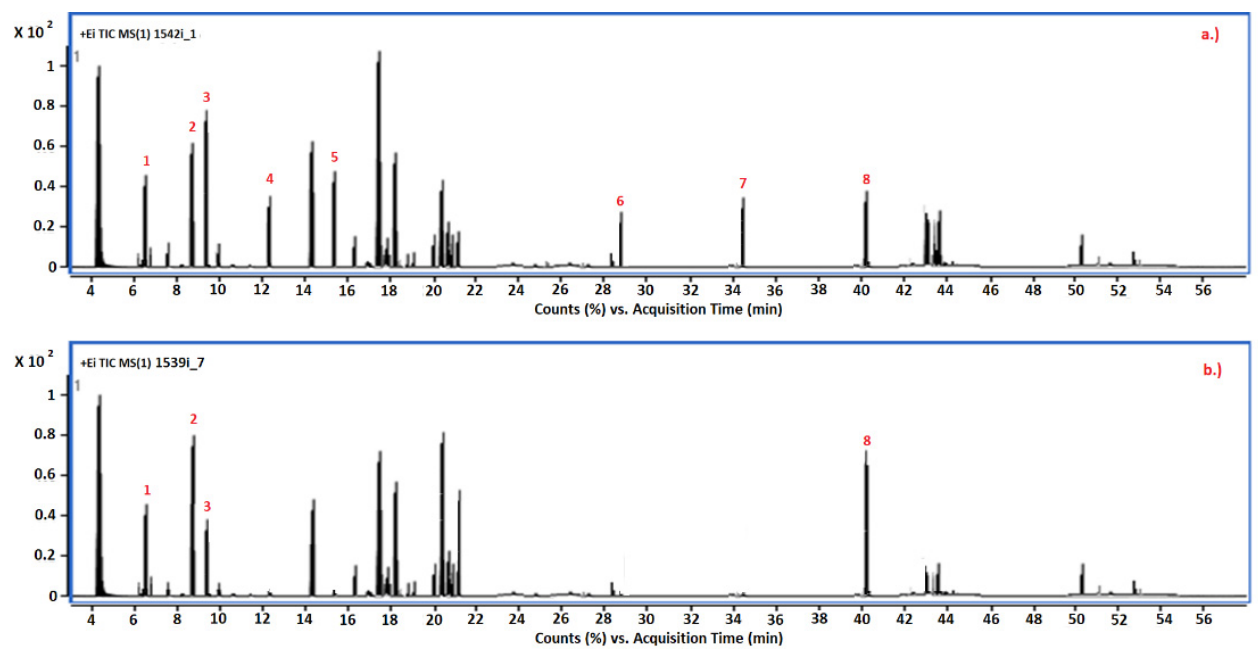

Figure 1. Total ion chromatogram of sample 1542i_1 (a.) and 1539i_7 (b.) after GC-MS analysis. In chromatograms: 1 - benzene, 2 - ethylbenzene, 3 - acetophenone, 4 - styrene, 5 - butyldiglycol, 6 - n-tetradecane, 7 - n-hexadecane, 8 -n-heptadecane.

Analyzing the results obtained for each plastic component the following remarks can be made:

- CPU sockets of 1997 and 2003 computer main boards have similar composition, ABS as main component, followed by PP and PS. Even if PS have closed values for both CPU sockets, a significant decrease of ABS and PS can be observed from 1997 to 2003.

- IDE connectors of 1997 and 1998 computer main boards have similar composition, ABS as main component, followed by PP and PS. Even if ABS have closed values for both CPU sockets, a significant decrease of PP and PS can be observed from 1997 to 1998. 
- $\mathrm{PCl}$ Connector of 1997 computer main board - the main component is ABS followed by PS and PP.

- Floppy Connector of 1998 computer main board - PS and ABS are the main components having very closed values. Since the value of ethylbenzene, component of both PS and ABS cannot be correctly splinted between the two polymers, it is safer to suppose that $A B S$ is the main component.

- AGP Connector of 1998 and 2003 computer main boards have different composition. The one from 1998 has PP as main component, followed by PS and PP while the one from 2003 has PS as main component, followed by ABS and PP. A significantly decrease of PP from 1998 to 2003 can be observed.

- Power Connector of 1998 computer main board - the main component is ABS followed by PS and PP which have very closed values.

- Socle RAM of 2003 computer main board - the main component is $\mathrm{PS}$ followed by ABS and PP.

The results obtained shows that for 1997-1998 computer main boards, in almost all cases, the main component is ABS (namely acetophenone) while for 2003 computer main board the main component is PS (namely benzene) in almost all case. Also, analyzing the results, a decrease of PP usage can be observed.

In this case, the GC-MS method developed proved to be a useful tool to determine the main components of major polymers from WEEE. It is quicker, more accurate and eco-friendly then other methods used previously.

\section{CONCLUSIONS}

The GC-MS method developed for characterization of WEEE major polymers proved to be quick, accurate and suitable for the declared purpose. The plastic components of 4 computer main board from 1997-2003 were analyzed, using the new analytical method, in order to establish the main polymer component. Three types of plastic polymers were approximately measured: polystyrene (PS), acrylonitrile butadiene styrene (ABS) and polypropylene (PP). Their percentage in the samples were quantified using the major volatile organic compounds from their composition. The results suggest that for 1997-1998 computer main boards the main component is ABS while for 2003 computer main board the main component is PS. A significantly decrease of PP usage can be observed for 2003 computer main board plastic components comparing with the values obtained for 1997-1998 computer main boards plastic components. 


\section{EXPERIMENTAL SECTION}

\section{Materials}

The extraction was carried out using anhydrous $\mathrm{NaCl}$ with $\geq 99.5 \%$ purity purchased from Sigma Aldrich. HiQ Helium 6.0 used as carrier gas was purchased from Linde. Ultrapure water was obtained using a type I ultrapure water system Flex3 Elga Veolia.

\section{Instrumentation}

The measurements were carried out using 7890 GC-MS from Agilent. Separation of volatile organic compounds was performed using a HP-5ms fused-silica capillary column of $30 \mathrm{~m}$ length $\times 0.25 \mathrm{~mm}$ I.D. $\times 0.25 \mu \mathrm{m}$ film thickness (Restek, USA) after their extraction on 50/30 $\mu \mathrm{m}$ DivinylbenzeneCarboxen/Poly(dimethylsiloxane) (DVB-CAR/PDMS) SPME fibre (Supelco).

Table 1. Plastic composition of $1997-2003$ computer main boards plastic components

\begin{tabular}{|c|c|c|c|c|c|c|c|c|c|c|c|c|}
\hline \multirow{4}{*}{ No } & \multirow{4}{*}{$\begin{array}{l}\text { Volatile organic } \\
\text { compounds }\end{array}$} & \multirow{4}{*}{ M.U. } & \multicolumn{10}{|c|}{ Sample identification (code/description) } \\
\hline & & & $\begin{array}{l}\text { 1542i_1 } \\
\text { CPU } \\
\text { Socket }\end{array}$ & \begin{tabular}{|l|} 
1542i_2 \\
Ide \\
Connector
\end{tabular} & \begin{tabular}{|l|} 
1542i_3 \\
PCl \\
Connector
\end{tabular} & \begin{tabular}{|l|} 
1539i_10 \\
Floppy \\
Connector
\end{tabular} & \begin{tabular}{|l|} 
1539i_7 \\
AGP \\
Connector
\end{tabular} & \begin{tabular}{|l|}
$1540 \mathrm{i} \_8$ \\
IDE \\
Connector
\end{tabular} & \begin{tabular}{|l|}
$1540 i \_9$ \\
Power \\
Connector
\end{tabular} & $\begin{array}{l}1541 i \text { 4 } \\
\text { CPU } \\
\text { Socket }\end{array}$ & $\begin{array}{l}\text { 1541i_5 } \\
\text { Socle } \\
\text { RAM }\end{array}$ & $\begin{array}{l}\text { 1541i_6 } \\
\text { AGP } \\
\text { Connector }\end{array}$ \\
\hline & & & \multicolumn{10}{|c|}{ Year of fabrication } \\
\hline & & & \multicolumn{2}{|r|}{1997} & & \multicolumn{2}{|l|}{1998} & \multicolumn{2}{|r|}{1998} & & \multicolumn{2}{|l|}{2003} \\
\hline 1. & Benzene & $\%$ & 3.2 & 5.1 & 3.3 & 12.1 & 4.2 & 7.8 & 7.9 & 5.3 & 19.2 & 15.4 \\
\hline 2. & Ethylbenzene & $\%$ & 2.5 & 12.2 & 3.8 & 5.7 & 13.7 & 3.8 & 3.2 & 0.8 & 1.1 & 0.8 \\
\hline \multicolumn{2}{|c|}{ Polystyrene (PS) } & $\%$ & 5.7 & 17.3 & 7.1 & 17.8 & 17.9 & 11.6 & 11.1 & 6.1 & 20.3 & 16.2 \\
\hline 3. & Acetophenone & $\%$ & 21.8 & 17.2 & 15.2 & 11.5 & 5.1 & 14.2 & 25.9 & 12.8 & 3.4 & 6.7 \\
\hline 4. & Styrene & $\%$ & 2.9 & 2.1 & 1.9 & 2.8 & & 0.7 & 0.9 & 1.8 & 6.2 & 0.9 \\
\hline 5. & Butyldiglycol & $\%$ & 5.7 & 2.6 & 1.8 & 3.4 & 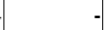 & 7.5 & 7.1 & 6.7 & & 0.8 \\
\hline \multicolumn{2}{|c|}{$\begin{array}{l}\text { Acrylonitrile butadiene } \\
\text { styrene (ABS) }\end{array}$} & $\%$ & 30.4 & 21.9 & 18.9 & 17.7 & 5.1 & 22.4 & 33.9 & 21.3 & 9.6 & 8.4 \\
\hline 6. & n-Tetradecane & $\%$ & 2.8 & 2.2 & 0.8 & 0.8 & 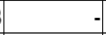 & 1.4 & $=$ & 1.7 & & \\
\hline 7. & n-Hexadecane & $\%$ & 4.7 & 6.2 & & 1.2 & & 2.1 & 0.6 & 6 & - & \\
\hline 8. & n-Heptadecane & $\%$ & 3.1 & 8.6 & 1.5 & 5.2 & 19.2 & 7.2 & 10.4 & 2.9 & 3.5 & 7.9 \\
\hline \multicolumn{2}{|c|}{ Polypropylene (PP) } & $\%$ & 10.6 & 17.0 & 2.3 & 7.2 & 19.2 & 10.7 & 11.0 & 4.6 & 3.5 & 7.9 \\
\hline
\end{tabular}

\section{Extraction and analytical methods}

a. Extraction. In order to extract the volatile compounds, plastic samples were chopped (Figure 2). Approximately $2.5 \mathrm{~g}$ of sample was placed in headspace vials and $5 \mathrm{~mL}$ of saline water solution (10\% saline content; w:v) was added before closing the headspace vials with Teflon/silicone disk and aluminum crimp cap. The SPME fibers were pre-conditioned according to the supplier's instructions in the GC injection port at $270{ }^{\circ} \mathrm{C}$. 
The vial and the SPME fiber were then placed into a heating block set at $55{ }^{\circ} \mathrm{C}$ and kept at this temperature for 30 min under continuous agitation. Volatiles compounds desorption from SPME fiber was allowed for $7 \mathrm{~min}$ in the GC injection port.
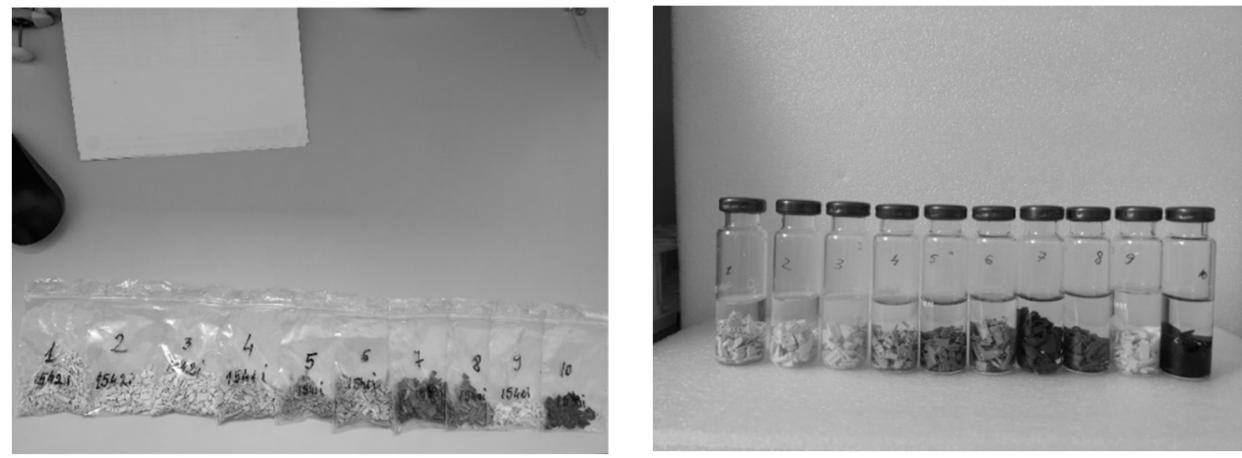

Figure 2. Chopped plastic materials (left) and Headspace extraction of volatile compounds from plastics (right)

b. GC/MS analysis. A GC/MS analytical method was developed in order to identify the most important compounds of polystyrene (PS), acrylonitrile butadiene styrene (ABS) and polypropylene (PP): Benzene, Ethylbenzene, Styrene, Acetophenone, Butyldiglycol, $\mathrm{n}$-Tetradecane, $\mathrm{n}$-Hexadecane and $\mathrm{n}$ Heptadecane. Helium was used as carrier gas with a constant flow of $1 \mathrm{~mL} / \mathrm{min}$. The split/splitless injector was used in splitless mode and its temperature was maintained at $270{ }^{\circ} \mathrm{C}$. The column oven temperature program for separation of volatile compounds was $40{ }^{\circ} \mathrm{C}(5 \mathrm{~min})$ to $110^{\circ} \mathrm{C}(5 \mathrm{~min})$ at $10^{\circ} \mathrm{C} / \mathrm{min}$ and followed by an increase at $250^{\circ} \mathrm{C}(5 \mathrm{~min})$ at $10^{\circ} \mathrm{C} / \mathrm{min}$. The $\mathrm{GC} / \mathrm{MS}$ interface was set at $270{ }^{\circ} \mathrm{C}$ and the ion source was held at $280^{\circ} \mathrm{C}$. Mass spectra were acquired under electron ionization mode (EI) at $70 \mathrm{eV}$ and recorded in the range $\mathrm{m} / \mathrm{z}$ 50-650 at one cycle per second. The chromatographic peaks were identified either by direct analysis of the mass spectrum or/and comparison with a reference mass spectral library (US National Institute of Standards and Technology, NIST 02 version 2.0a, 2002). The analytical parameters of the calibration curves are presented in Table 2. For each compounds single component analytical standards were used (Sigma-Aldrich, Darmstadt, Germany). Each concentration was prepared in $5 \mathrm{~mL}$ of saline water solution and analyzed after SPME fiber desorption in the same condition as samples. 
Table 2. Calibration curves parameters of investigated compounds

\begin{tabular}{|l|c|c|c|c|c|}
\hline \multicolumn{1}{|c|}{ Compound } & Calibration curve & $\begin{array}{c}\text { Range } \\
\text { (ug/L) }\end{array}$ & $\begin{array}{c}\text { Correlation } \\
\text { coefficient }\end{array}$ & LOD & LOQ \\
\hline Benzene & $\mathrm{Y}=2376.3 \mathrm{x}+617.97$ & $0.5-25$ & 0.9956 & 0.118 & 0.354 \\
\hline Ethylbenzene & $\mathrm{Y}=3321.8 \mathrm{x}-438.47$ & $0.5-25$ & 0.9995 & 0.215 & 0.645 \\
\hline Styrene & $\mathrm{Y}=1831 \mathrm{x}+2575$ & $0.5-25$ & 0.9957 & 0.145 & 0.435 \\
\hline Acetophenone & $\mathrm{Y}=3840.3 \mathrm{x}-1718$ & $0.5-10$ & 0.9977 & 0.215 & 0.645 \\
\hline Butyldiglycol & $\mathrm{Y}=3946.4 \mathrm{x}+1839.5$ & $0.5-10$ & 0.9986 & 0.321 & 0.963 \\
\hline n-Tetradecane & $\mathrm{Y}=741.39 \mathrm{x}-474.73$ & $0.5-50$ & 0.9961 & 0.115 & 0.345 \\
\hline n-Hexadecane & $\mathrm{Y}=1146.7 \mathrm{x}+285.24$ & $0.5-50$ & 0.9988 & 0.258 & 0.774 \\
\hline$n$-Heptadecane & $\mathrm{Y}=3038 \mathrm{x}-94.814$ & $0.5-50$ & 0.9986 & 0.082 & 0.246 \\
\hline
\end{tabular}

\section{ACKNOWLEDGMENTS}

The work has been funded by the PNCDI III - Program 1 Complex projects completed in consortia CDI - 2017, TRADE-IT, PN-III-P1-1.2PCCDI-2017-0652, contract no. 84PCCDI/2018.

\section{REFERENCES}

1. https://ec.europa.eu/environment/waste/weee/index_en.htm

2. P.A. Wäger; M. Schluep; E. Müller; R. Gloor; Environ. Sci. Technol., 2012, 46 (2), 628-635.

3. I.C. Nnorom; O. Osibanjo; Resour. Conserv. Recycl., 2008, 52, 1362-1372.

4. L.E. Peisino; M. Gómeza; J. Kreikera; R. Gagginoa; M. Angelelli; Sustain. Chem. Pharm., 2019, 12, 1-5.

5. C. Guo; Q. Zou; J. Wang; H. Wang; S. Chen; Y. Zhong; Waste Manag., 2018, 82,167-176.

6. Y.V. Vazquez; S.E. Barbosa; Multidiscip. J. Waste Res. Resid., 2018, 2, 105-111.

7. G. Martinho; A. Pires; L. Saraiva; R. Ribeiro, R., Waste Manag., 2012, 32, 1213-1217.

8. E. Maris; P. Botané; P. Wavrer; D. Froelich; Miner. Eng., 2015, 76, $28-37$.

9. J. Wang; Y. Li, J. Song; M. He; J. Song; K. Xia, K., Polym. Degrad. Stab., 2015, 112, 167-174.

10. C.B. Crawford; B. Quinn; Physiochemical properties and degradation, In Microplastic Pollutants, Elsevier Inc., Amsterdam, Holland, 2017, Chapter 4, pp. 57-100.

11. https://en.wikipedia.org/wiki/Polystyrene 
12. F. Wagner, J. Peeters, J. De Keyzer, J. Duflou, W. Dewulf, Proc. EcoDesign 2017 Intl. Sym., 2017, 1-9.

13. J.C. Arnold, T.Watson, S. Alston, M. Carnie, C. Glover, Polymer Testing, 2010, 29(4), 459-470.

14. H. Yan, H. W. Siesler, Identification performance of different types, Appl. Spectrosc., 2018, 72, 1362-1370.

15. R. Naushad, M.H. Vijayam, A.M. Hassan, T.S. Rashid, S. Asha, AIP Conf. Proc., 2020, 2222(1), 1-6.

16. V. Allen, J.H. Kalivas, R.G. Rodriguez, Appl. Spectrosc., 1999, 53(6), 672-681.

17. A. Tsuchida, H. Kawazumi, A. Kazuyoshi, T. Yasuo, SENSORS, 2009 IEEE, 2009, pp. 1473-1476.

18. F. Puype, J. Samsonek, V. Vilímková, Š. Kopečková, A. Ratiborská, J. Knoop, M. Egelkraut-Holtus, M. Ortlieb, U. Oppermann, Food Addit. Contam.: Part A, 2017, 34(10), 1767-1783.

19. W.J. Hall, P.T. Williams, J. Anal. Appl. Pyrolysis, 2007, 79(1-2), 375-386. 